\title{
AGE CHANGES IN THE THYMUS- A HISTOLOGICAL AND MORPHOLOGICAL STUDY
}

Sheela Sivan, Angela A. Viswasom, Krishnan B

1. Associate Professor. Department of Anatomy, MES Medical College. Perinthalmanna.

2. Associate Professor. Department of Anatomy, MES Medical College. Perinthalmanna.

3. Associate Professor. Department of Forensic Medicine, MES Medical College. Perinthalmanna.

\section{CORRESPONDING AUTHOR:}

Dr. Angela A. Viswasom,

Associate Professor, Department of Anatomy,

Travancore Medical College, Medicity,

N H Bypass, Umayanalloor P. 0 ,

Kollam- 691589.

E-mail: drangelakrishnan@yahoo.com

ABSTRACT:_A histological and morphological study of human thymus obtained from autopsy was done. A steady increase in weight of thymus till puberty and thereafter a steady decline was noted. Involution was by fatty infiltration after puberty. Hassall's corpuscles were seen in all the specimens and its size or shape had no relation to the age or involution of the gland. There was an increase in the number of Hassall's corpuscles till puberty after which a progressive decrease was observed.

KEY WORDS: Human thymus, weight, age changes, Hassall's corpuscles

INTRODUCTION: The human thymus located in the anterior and superior mediastinum is a tissue which is minimally visualized during dissection. This is mainly because the organ regresses with age. This study was conducted to establish a relation between age and changes related to the thymus. The specimens were obtained from postmortem studies and also from dead fetuses. Weight was estimated using a common balance while slides were prepared to analyse the histological changes.

On the basis of autopsy studies it has been shown that the thymus grows rapidly during embryonic life and childhood reaching a maximum absolute size about the time of puberty. Thereafter, growth ceases and it involutes gradually until old age, when the gland is often smaller than at birth (Hammar, 1926, 9).

The weight of thymus increases from birth till puberty \& its maximum weight in relation to body weight is attained during the last few months of fetal life and wide range of variations occur at different ages (Edwin.R.Fisher, 1968, 5).

Age involution is shown by decrease in the overall weight of the organ associated with lymphoid tissue atrophy and replacement by adipose tissue. (Young \& Turnbull, 1931, ${ }^{20}$ ).

In characterizing the physiological involution of the mammalian thymus, the term "Alters involution" referring to age related involution is used (Bodey B, 1997, ${ }^{2}$ ).

E.Erola (1981) et. al. ${ }^{6}$ commented that lymphocytes started to disappear first at the corticomedullary junction which gradually broadened giving rise to lymphoid epithelial fragments.

Thymic involution has been envisaged as an extremely complex process involving multifactorial mechanisms along the bone marrow thymic axis that accounts for the major 
manifestations of immunosenescence. A causal link has been established with thymic involution and the rise in gonadal steroid levels at puberty. (Leposavic and Perisic, 2008, 15)

Hammar (1926) ${ }^{9}$ described that Hassall's corpuscles were formed hypertrophy of reticular cells with degeneration beginning in the centre.

Hassall's corpuscles in the thymus are formed from degeneration of compact masses of reticular cells. It is observed that the corpuscle formation is around hypertrophied reticular cells and degenerated vessels (Kostowiecki, 1930, 13).

Paul Kohnen $\left(1964,{ }^{17}\right)$, in a study of thymic corpuscles in guinea pig suggested that the central core of Hassall's corpuscle consists of reticular cells with lamellation.

The study reflects on the changes in the thymus and shows that the thymus weighs the most during puberty and also has the maximum number of Hassall's corpuscles during the same period.

MATERIALS AND METHODS: Fifty two specimens were studied out of which thirteen were from dead foetuses and the rest from autopsies. Foetuses belonged to the age group of $4^{\text {th }}$ month of intrauterine life to full term .The rest of the specimens were divided into eight groups according to the age. The first group from the age of 0-10 years and the last group falling into the age group of 70-80 years.

TABLE 1. Age-wise distribution of the material studied

\begin{tabular}{|l|l|l|l|l|l|l|l|l|l|}
\hline Age in years & Fetus & $\begin{array}{l}0- \\
10\end{array}$ & $\begin{array}{l}11- \\
20\end{array}$ & $\begin{array}{l}21- \\
30\end{array}$ & $\begin{array}{l}31- \\
40\end{array}$ & $\begin{array}{l}41- \\
50\end{array}$ & $\begin{array}{l}51- \\
60\end{array}$ & $\begin{array}{l}61- \\
70\end{array}$ & $\begin{array}{l}71- \\
80\end{array}$ \\
\hline $\begin{array}{l}\text { Number of } \\
\text { specimens }\end{array}$ & 13 & 8 & 6 & 6 & 3 & 5 & 4 & 4 & 3 \\
\hline
\end{tabular}

The adult thymus specimens were obtained during routine postmortem after sternotomy. Dead fetuses were collected from the labour room and were dissected/ Sternotomy was done using bone cutter after reflecting the skin along the median plane. The specimen was removed from in front of the pericardium enmasse using forceps and blunt tipped scissors. The weight of the dissected thymus specimens was noted using a common balance. The specimens were fixed in Bouin's fluid. Three tissue bits were taken from upper, middle and lower parts of the lobes of each specimen. These tissues were routinely processed and stained using haematoxylin and eosin for routine light microscopy. Adipose tissue content of the specimens was studied using osmium tetroxide as special stain. (John.D.Bancroft,10)

Stained sections were studied under low power, high power, and oil immersion using a light microscope. The number of Hassall's corpuscles was counted under low power. Five different fields of the same section were observed and an average was taken. (Evans 1966,7)

OBSERVATIONS: Weight of thymus: In fetuses upto 8 months, the average weight was in the range of 3-8 gms, whereas in the two full term fetuses, thymus weighed $17 \mathrm{gms}$ each.

In the age group of 0-10 years there was a wide variation. It ranged between $16-40 \mathrm{gms}$ with an exception of 4 months old male baby in which the thymus weighed 54gms. Weight of the thymus varied from 16 to $40 \mathrm{gms}$, in the age group of 0-10 years, thereby registering a wide range of variation. Thymus from a 4 month old male baby weighed $54 \mathrm{gms}$. In our series, the 
weight of thymus then showed a steady increase with age towards puberty reaching $55 \mathrm{gms}$ in the specimen of 13 year old child. Thereafter a steady decline in the weight was observed. Weight of the thymus showed a decrease reaching an average of 20-25gms in age group of 2130 years and 10-20gms above 30 years. (Fig. 1)

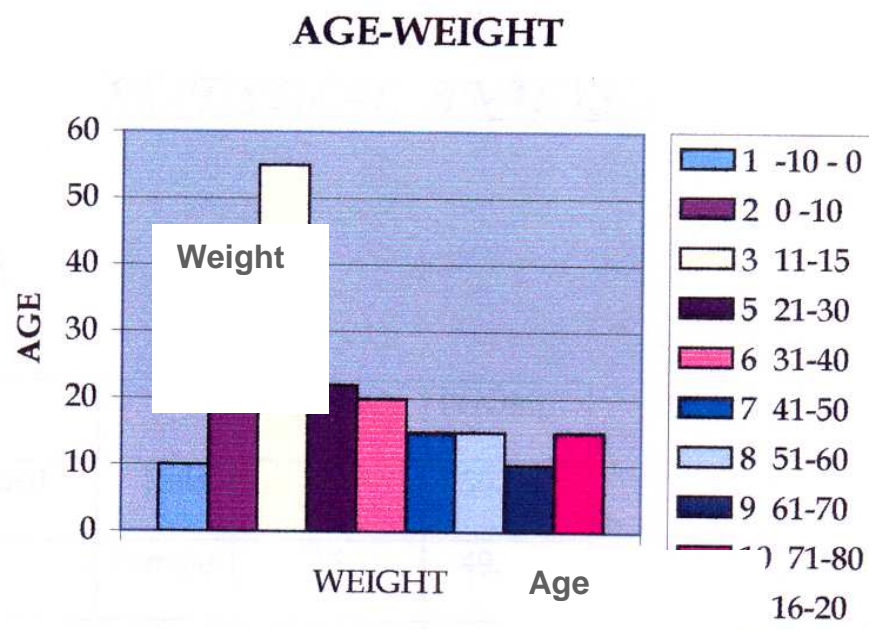

Fig. 1 : Age-wise distribution of wergm ur unymus (in grams)

MICROSCOPIC STRUCTURE AND NUMBER OF HASSALL'S CORPUSCLE IN THYMUS: Foetal thymus showed a well defined cortex and medulla. Lymphocytes were thickly packed in the cortex \& less densely packed in the medulla. Hassall's corpuscles were seen in all the specimens but with varying number, size, and shape. Hassall's corpuscle could be identified even in the youngest fetus of 4 months age. This showed a central eosinophilic mass surrounded by few nucleated cells. Reticulocytes could be identified in all the specimens. Few fat cells were observed in the connective tissue septa of a full term fetus.

In the age group of 0-10 years, thymus was lobulated showing well differentiated cortex and medulla. Reticulocytes could be identified. Medulla exhibited a number of Hassall's corpuscles which varied in size and shape. Fat cells could be seen in the thymus of a $2^{1 / 2}$ year old child.

Thymus in the age group of 11-20 exhibited normally lobulated thymus with Hassall's corpuscles in the medulla. However, infiltration of fat was observed in the specimens from the age of 16 years onwards. The fatty infiltration was seen to increase from the year 20 onwards. Distribution of reticulocytes and presence of varying number of Hassall's corpuscles were observed. A few of the Hassall's corpuscles exhibited capillaries within them. The specimen obtained from the age group 51-60 years, showed that the thymic tissue was invaded by fat and lymphocytes were few in number.

It was noted that there was an increase in amount of thymic tissue in two 79 year old specimens. Hassall's corpuscle present in the tissue was of typical arrangement. Reticulocytes could be identified between the lymphocytes.

In the age group 61-70, thymic tissue was found to be replaced by fat and the lobulation had disappeared. However, two of the specimens from 79 year old specimens showed normally lobulated thymus with reticulocytes and Hassall's corpuscles.

The number of Hassall's corpuscles per low power field was assessed in all the specimens. There was an increase in the number of Hassall's corpuscles till puberty after which 
a progressive decrease was observed. In the age group of 71-80 there was an increase in the number of Hassall's corpuscles.

STATISTICAL ANALYSIS: The mean weight of the thymus (gms) was observed to be 18.06 with a standard deviation of 11.73 from the median value of 18.00 .

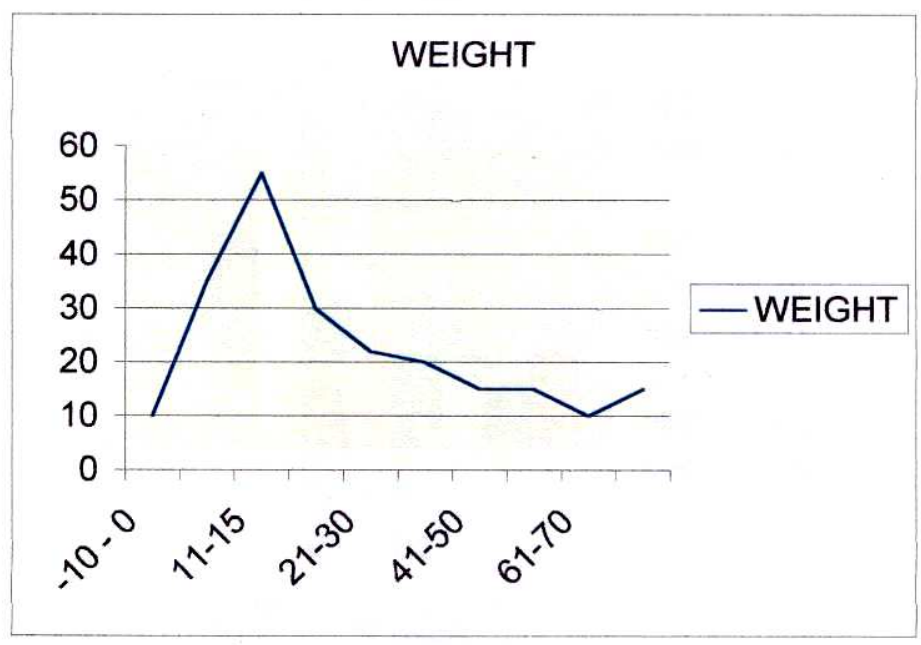

\section{Fig.7Age-wise distribution of weight of thymus (in grams)}

Mann - Whitney test showed that there is no significant difference in the number of Hassall's corpuscles in between the two sexes.

Spearman's correlation coefficient of age wise distribution of the number of Hassall's corpuscles was -0.202 , and the $P$ value was found to be significant.

Analysis of variance (ANOVA) of Hassall's corpuscles with age showed significant differences between the groups.

Regression graphs were plotted and a cubic curve was obtained which coincided with the observed number of Hassall's corpuscles. The $\mathrm{R}$ square value showed a significant correlation between the number of Hassall's corpuscle and age. According to the cubic method the variability can be predicted in $36 \%$.

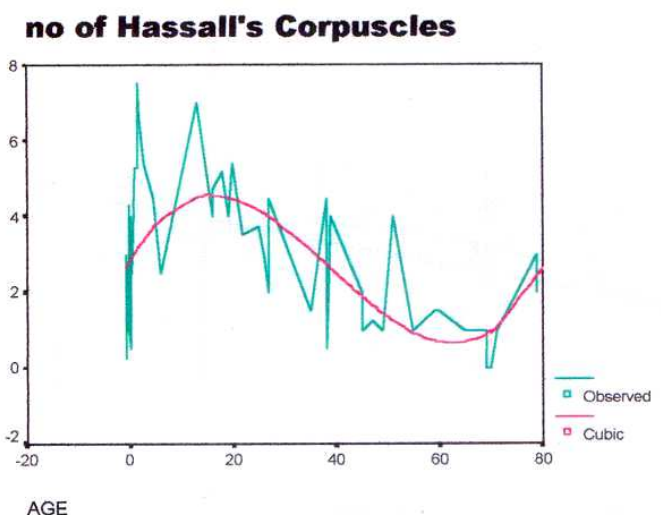

Fig.8 Age-wise distribution of number of Hassall's corpuscles per low power field 
DISCUSSION: Our observation that the weight of the thymus increased in weight in relation to the age until puberty and decreased thereafter is in agreement with the studies of Scammon $\left(1927,{ }^{18}\right)$, Turnbull $\left(1931,{ }^{20}\right)$ and Edwin R. Fischer $(1968,5)$.

Fatty infiltration of thymic tissue starts after puberty \& the cortex was infiltrated first. The fat cells which invaded the thymic tissue was probably from the connective tissue septa. As age advances fatty infiltration increases with most of the thymic tissue being replaced by fat. (Young and Turnbull 1931,20)

Hassall's corpuscles were observed in all the specimens studied. The age and weight of the thymus had no effect on the number or size of the Hassall's corpuscles. Jordan \& Hosely $\left(1927,{ }^{11}\right)$ thought that Hassall's corpuscles were formed by proliferation of capillaries. Dreath $(1928,4)$ said it was due to the proliferation of epitheliocytes. This study does not agree with the above views because there were no signs of proliferation of epitheliocytes. This work agrees with the opinion of Kostowecki $\left(1938,{ }^{14}\right)$ which states that Hassall's corpuscles are formed by hypertrophy of epitheliocytes with some degenerative changes occurring to them. Some corpuscles showed sections of capillaries.

The cortex was observed to be invaded by adipose tissue. This is suggestive of the fact that as age advances the cortex looses its functional significance because sufficient number of $\mathrm{T}$ lymphocytes has already been formed. Taylor Brown et al $\left(2009,{ }^{19}\right)$ states that the age associated involution of thymus has a major impact in the decline in immunity in elderly people as thymus is crucial for T cell output. The presence of Hassall's corpuscles in the medulla in all age groups indicate some function. Their persistence as age advances points to the functional importance even in old age.

There have been reports on functional significance of thymus. Doughtery $(1952,3)$ had studied the effect of hormones on thymus, where he had shown adrenal and gonadal hormones produced atrophy of thymus. Bellamy et al $\left(1976,{ }^{1}\right)$, in his study of rat thymus observed that the maximum weights of thymus attained in gonadectomized animals were found to be independent of the age at which the animals were gonadectomized or of the sex of the animal.

Fitzpatrick $\left(1985,^{8}\right)$ observed reappearance of thymus after orchidectomy. Once again, Kendall's $\left(1990,{ }^{12}\right)$ work shows reappearance of thymus after chemical castration which confirms the effect of gonadal hormones on thymus. Min H $(2006,16)$ suggested that the concomitant decline in growth hormone and increase in sex steroid production with age is thought to be responsible for thymic involution. Leposavic et al $(2008,15)$ stated that onset of age associated thymic involution coincides with a rise in gonadal steroid levels at puberty. In this work an increase in amount of thymic tissue is seen in age above 70 years. This suggests that the changes in the level of gonadal hormones play a vital role in thymic involution.

SUMMARY: The weight of thymus increases steadily from intrauterine life till puberty and thereafter there is a steady decline. Hassall's corpuscles are present in all age groups and there is no relationship of the size or shape with the age of the person. There was an increase in the number of Hassall's corpuscles till puberty after which a progressive decrease was observed. In the age group of 71-80 there was an increase in the number of Hassall's corpuscles. The thymus is infiltrated with fat after puberty and most of the thymic tissue is replaced with fat. Medulla with Hassall's corpuscles is retained even in the oldest specimen. After the age of 70 years there is an increase in amount of thymic tissue. The findings of this study are consistent with the concept of the thymic cellular microenvironment acting as the "clock" of the mammalian ageing process. 


\section{REFERENCES}

1. Bellamy D., Hinsull S.M., Phillips J.G. (1976) Factors controlling growth and age involution of the rat thymus. Age Ageing February 5 (1); 9-12.

2. Bodey B, Bodey B Jr, Siegel S.E., Kaiser H.E.(1997). Involution of the mammalian thymus, one of the leading regulators of aging. In vivo,1997 Sept- Oct; 11 (5): 421-40.

3. Doughtery T.F.(1952). Effect of hormones on lymphatic tissue. Physiol-Rev- 32: 379401.

4. Dreath 0.A.\& Kingsbury B.F.(1928). The nature and significance of the thymic corpuscles. Am.J.Anat.41: 321-351.

5. Edwin.R.Fisher (1968). The thymus. Endocrine, Pathology.Ed.by J.M.B.Bloodworth. The Williams\& Wilkins Co :197.

6. Erola.E, Ekfors.T, Tammi.R, Ruuskanen.O.(1981). Thymic morphology during in vitro culture. Anat. Rec. 200: 481-489.

7. Evans W.C. (1966) Quantitative microscopy: Trease and Evans Pharmacognosy W.D. Saunders Co. Ltd. (14th Edition) : 704-705.

8. Fitzpatrick F.T., Kendall M.D., Wheeler M.J., Adcock I.M. \& Greenstein B.D.(1985). Reappearance of thymus of ageing rats after orchidectomy. J. Endocrinology 106: R1729.

9. Hammar.J.A.(1926). DieMenschenthymus in Gesandhiet cut Krankhiet, I Das. Normale organ. Anat.Forsch 6:1., Page : 570. Cited by Robert.A. Good, Carlos Martinez \& Ann. E.Gabrielsen in the thymus in immunobiology, Harper \& Row, 1964, 721.

10. John.D. Bancroft \& M.Gamble. Theory \& Practice of Histological Technique Churchil Living Stone (6 ${ }^{\text {th }}$ Edition) $: 59$.

11. Jordan H.E.\& G.W.Horsely.(1927). The significance of the concentric corpuscles of Hassall. Anat. Rec.35: 729-732.

12. Kendall M.D., Fitzpatrick F.T., Greenstein B.D., Kohoylou F., Safieh B., Hamblin A.(1990). Reversal of ageing changes in the thymus of rats by chemical or surgical castration. Cell Tissue Res. 261(3) : 555-564.

13. Kostowiecki, M.(1930). Uber die Beziehung der Hassallschen Kiirperchen zu den benachbarten Blutgefiissen in der Thymus menschlicher Foeten. Bull.Internat. Acad. polon. d.sc.de Cracovie, Sc. Nat. (s.b.), (Zoological section) nos9-10, pp.589

14. Kostowiecki , M. (1938) Uber die Nervenfasern Nervenendigungen und in der Thymus w Shrend der Fetalperiode. Journal Zoologica Poloniae, 3.

15. Leposavic G., Perisic M.(2008). Age associated remodeling of thymopoiesis, Role for gonadal hormones and catecholamines. Neuroimmunomodulation. 15(4-6):290-322.

16. Min H., Montecino- Rodriguez E., Dorshkind K. (2006) Reassesing the role of growth hormones and sex steroids in thymic involution. Clin Immunol Jan 118 (1) 117-23.

17. Paul Kohnen \& Leon Weiss (1964). An electron microscopic study of thymic corpuscles in guinea pig. Anat Rec. 198: 29-33.

18. Scammon R.E. (1927). The prenatal growth of the human thymus. Proceedings of the Society for Experimental Biology and medicine. 24:906-909.

19. Taylor Brown F., Aw D., Cooper K., Palmer D.B.(2009). Phenotypical and morphological changes in thymic microenvironment from ageing mice. Biogerentology 10(3):311-22.

20. Young M. \& Turnbull H.M.(1931) An analysis of the data collected by the status lymphaticus investigations committee. Journal of Pathology \& Bacteriology. 34:213-258 


\section{ORIGINAL ARTICLE}

\section{AGE-NO:OF CELLS}



Fig. 2.Age-wise distribution of number of Hassall's corpuscles per low power field



Fig 3: Section of fetal thymus showing well defined cortex and medulla. Haematoxylin \& eosin staining. Magnification X 100 


\section{ORIGINAL ARTICLE}

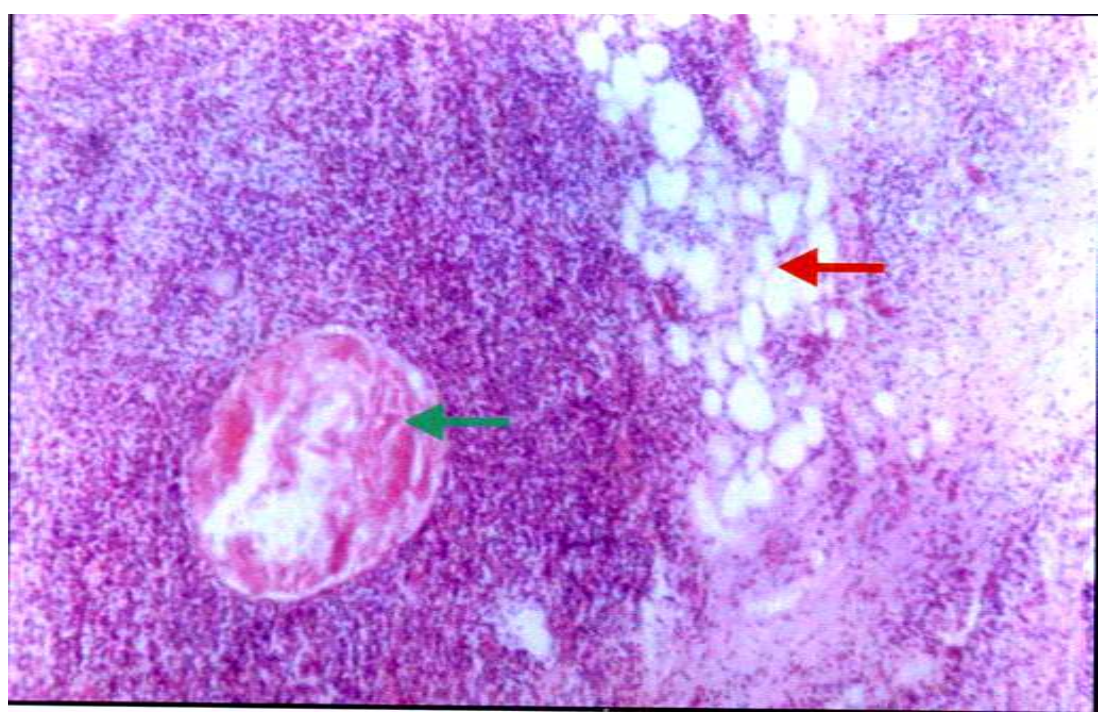

Fig.4 : Section of thymus of 16 year old male showing beginning of fatty infiltration. Haematoxylin \& eosin staining. Magnification X 100 ( Red arrow indicates fat, Green arrow indicates Hassall's corpuscle)

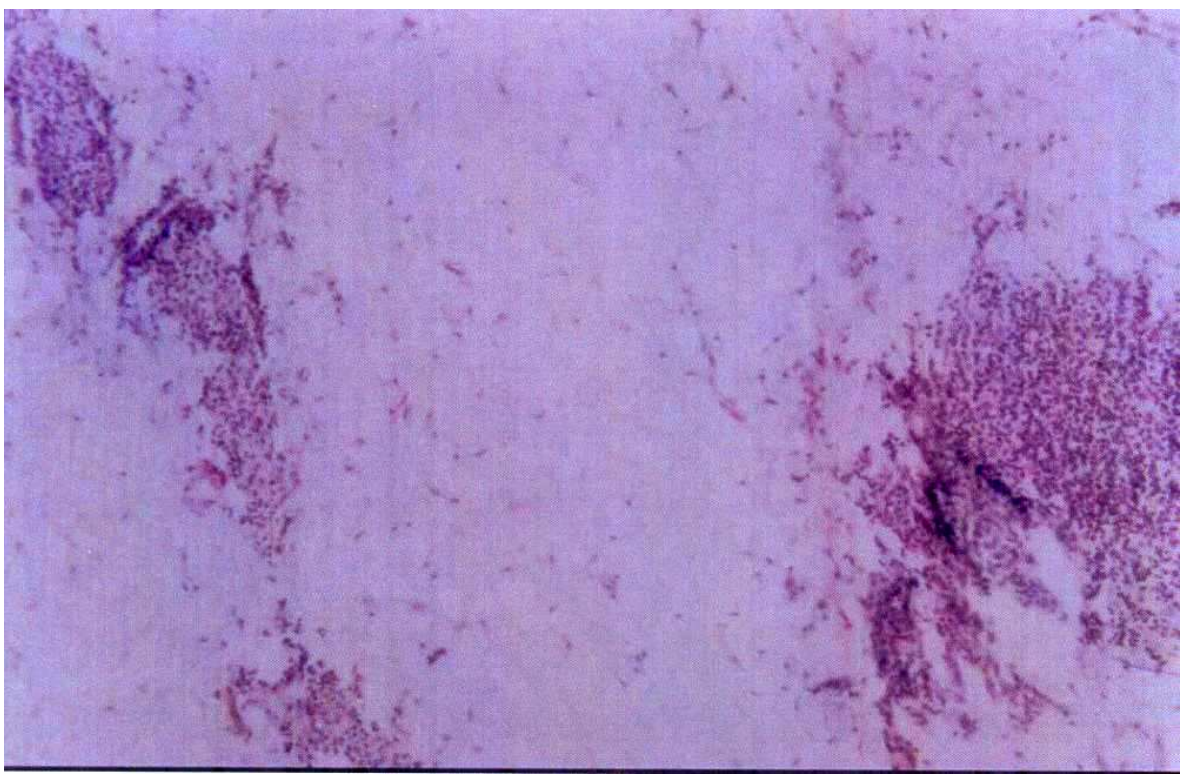

Fig.5: Section of thymus of 69 year old male showing streaks of thymic tissue.

Haematoxylin \& eosin staining. Magnification X 100 


\section{ORIGINAL ARTICLE}

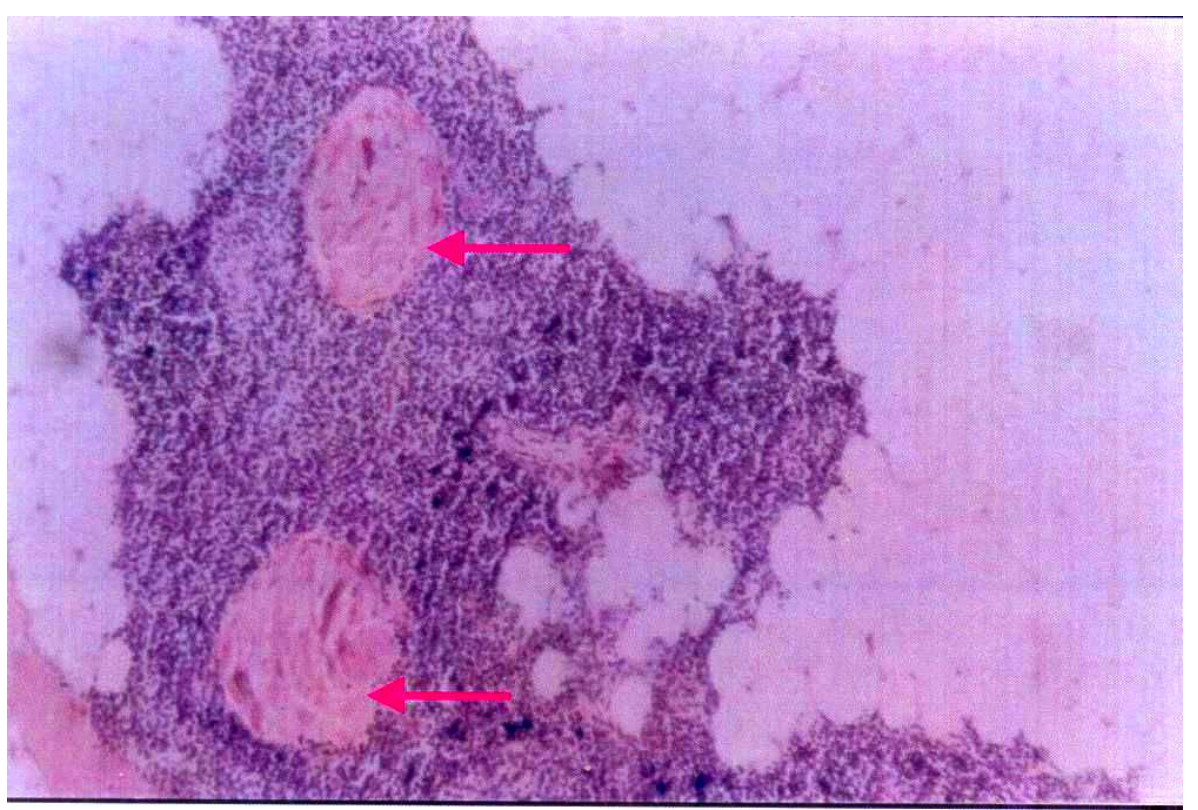

Fig.6: Section of thymus of 79 year old female showing thymic tissue and large Hassall's corpuscles.Haematoxylin \& eosin staining. Magnification X 100

(Red arrow indicates Hassall's corpuscle) 